\title{
Prevalence and antimicrobial susceptibility pattern of methicillin-resistant Staphylococcus aureus (MRSA) in CMS-teaching hospital: a preliminary report
}

\author{
R. K. Sanjana ${ }^{1}$, Rajesh Shah ${ }^{2}$, Navin Chaudhary $^{2}$, Y.I. Singh ${ }^{3}$ \\ ${ }^{1}$ Assistant Professor, ${ }^{2}$ Lecturer, ${ }^{3}$ Prof \& Head, Dept. of Microbiology, College of Medical Sciences-Teaching Hospital, \\ Bharatpur, Chitwan District, Nepal.
}

\begin{abstract}
s
Aims: Nosocomial infection is a major problem in the world today. Methicillin- resistant Staphylococcus aureus (MRSA) strains, usually resistant to several antibiotics and also intrinsic resistance to $\beta$ - lactam antibiotics, shows a particular ability to spread in hospitals and now present in most of the countries. The present study was carried out to investigate the prevalence of MRSA and their rate of resistance to different antistaphylococcal antibiotics.
\end{abstract}

Materials and methods: Between April 2007 and December 2009, the clinical specimens submitted at the microbiology laboratory were processed and all Staphylococcus aureus (S. aureus) isolates were included in this study. All isolates were identified morphologically and biochemically by standard laboratory procedures and antibiotic susceptibility pattern including oxacillin was determined by modified Kirby Bauer disc diffusion method.

Results: Out of a total of 348 Staphylococcus aureus strains isolated from various clinical samples, 138 (39.6\%) were found to be Methicillin- resistant. Among MRSA isolates, 86(62.3\%) were from different inpatient departments, whereas, 52(37.7\%) of the isolates were from outpatients. All MRSA were resistant to penicillin. More than 70\% of the MRSA strains were resistant to cephalexin, ciprofloxacin and cloxacillin, while less than $10 \%$ of them were resistant to azithromycin, amikacin and tetracycline. Many MRSA strains were multidrug resistant. However, no strains were resistant to vancomycin.

Conclusion: This preliminary report showed a high prevalence of MRSA in our hospital. To reduce the prevalence of MRSA, regular surveillance of hospital acquired infection and isolation is the need of the hour.

Key words: Nosocomial infection, methicillin-resistant Staphylococcus aureus (MRSA), multidrug resistant.

Correspondence: Dr. R. K. Sanjana

E-mail:Rajkumari_sanjana@yahoo.co.in 


\section{Introduction}

Staphylococcus aureus is a leading cause of hospital acquired infection (HAI) and over the past 50 years it has acquired resistance to previously effective antimicrobials including the penicillinase resistant ones like methicillin. ${ }^{1}$ Today, methicillin resistant Staphylococcus aureus(MRSA) has emerged as one of the most important nosocomial pathogens. ${ }^{2}$ The percentage of hospitals isolating MRSA in the developed countries has increased from $2 \%$ in the 70 's to $30 \%$ in the 90 's. ${ }^{3}$ Moreover, half of $S$. aureus in many centres are methicillin resistant(multidrug resistant) posing major therapeutic challenge. ${ }^{4}$ MRSA causes more than $50 \%$ of HAI and are more virulent than the methicillin sensitive strains. ${ }^{5,6}$ Prompt diagnosis of MRSA infection is, therefore, important for patients, health care givers and for epidemiological purposes. Hospital acquired infection (HAI) gives an enormous burden to the health care system significantly affecting the patient's morbidity and mortality. It results in prolongation of hospital stay and hence higher bed occupancy rate with an attendant increase in the cost of hospitalisation. ${ }^{7,8}$ Surveillance of MRSA related infections especially in the hospital set up is required and has been doing in the developed countries. Not only that, the magnitude of the problem is yet to be quantified. This study is an attempt to assess the prevalence of methicillin resistant S. aureus (MRSA) infection and its antibiotic susceptibility pattern in this hospital.

\section{Materials and methods}

This study was based on retrospective data of samples sent from different wards and OPDs of College of Medical Sciences-teaching hospital, Bharatpur. Total strains of 348 S. aureus were isolated from pus, urine, sputum, wound swab, aural swab, blood, throat swab and urethral swab during April 2007 and Dec 2009. S. aureus was identified by conventional method. ${ }^{9}$ The antimicrobial susceptibility test was carried out using Kirby-Bauer's disc diffusion method modified and updated by Clinical and Laboratory Standards Institute guidelines (CLSI). ${ }^{10}$ Each of the strain was screened for oxacillin resistance using American Type Culture Collection (ATCC) 43300 as the control. A standard inoculum was prepared by direct colony suspension in and comparing it with $0.5 \mathrm{Mc}$. Farland turbidity. Using a sterile cotton swab and after removing the excess of the inoculum by pressing against the side of the tube, the suspension was inoculated on a Mueller Hinton Agar medium by lawn culture method all over the surface of the medium. Oxacillin disc (1 $\mu \mathrm{g})$, (HI Media Laboratories, Pvt. Ltd. Mumbai) was applied along with other antimicrobials for testing sensitivity and the plates were examined after an over night incubation at $37^{\circ} \mathrm{C}$. Zone of inhibition diameter (in $\mathrm{mm}$ ) were measured and results were interpreted as sensitive, resistant as per recommendation of Clinical and Laboratory Standards Institute guidelines (CLSI). Other antimicrobials tested were chloramphenicol $(30 \mu \mathrm{g})$, tetracycline $(30 \mu \mathrm{g})$, gentamicin $(10 \mu \mathrm{g})$, erythromycin $(15 \mu \mathrm{g})$, cotrimoxazole $(25 \mu \mathrm{g})$, cephalexin $(30 \mu \mathrm{g})$, ciprofloxacin $(5 \mu \mathrm{g})$, amikacin $(30 \mu \mathrm{g})$, cefotaxime $(30 \mu \mathrm{g})$ and vancomycin $(10 \mu \mathrm{g})$.

\section{Results}

Isolation of Staphylococcus was maximum in pus samples. Out of the 348 strains of $S$. aureus examined 138 (39.6\%) were found to be Methicillin- resistant and of which $86(62.3 \%)$ were from inpatient departments. Amongst them only 9 (10.4\%) of the 
isolates were from intensive care units (ICU). A total of $52(37.7 \%)$ MRSA strains were from outpatients. Maximum isolation of MRSA was from pus (53.3\%), followed by wound swabs (44.4\%), sputum (37.5\%), aural swabs (33.3\%) etc. (Table- 1 ) shows detection of MRSA in different samples. All the strains of MRSA were found to be resistant to Penicillin. (Table -2) depicts the antibiotic susceptibility data for all the $S$. aureus isolates. Among MRSA, resistance to cephalexin was $81.8 \%$, ciprofloxacin $-71.0 \%$, cloxacillin $-70.6 \%$, erythromycin $-58.0 \%$, gentamicin $-38.0 \%$, cefotaxim $-31.6 \%$, cotrimoxazole $-20.4 \%$, while amikacin, azithromycin and tetracycline were resistant to less than $10 \%$ of the MRSA strains. Many MRSA strains were multidrug resistant. No strain was resistant to vancomycin. However, $41.2 \%$ of Methicillin sensitive $S$. aureus (MSSA) were resistant to penicillin, $25.7 \%$ resistance to cephalexin, $25.4 \%$ resistance to ciprofloxacin, $16.6 \%$ resistance to cloxacillin, $14.5 \%$ resistance to erythromycin, $32.3 \%$ resistance to gentamicin as compared with MRSA. MSSA isolates also revealed higher susceptibility to cefotaxime, cotrimoxazole with a resistance rate of $9.3 \%$ and $9.8 \%$ of the strains respectively. None of the MSSA was resistant to azithromycin.

Table- 1: Isolation of MRSA from Specimens of outdoor and indoor patients in CMS-teaching hospital, Bharatpur, Nepal

\begin{tabular}{|c|c|c|c|c|c|c|c|}
\hline \multirow[t]{2}{*}{ S.No } & \multirow[b]{2}{*}{ Specimens } & \multicolumn{2}{|r|}{$O P D$} & \multicolumn{2}{|c|}{ Ward \& ICU } & \multicolumn{2}{|r|}{ Total } \\
\hline & & S. aureus & $\begin{array}{l}\text { MRSA } \\
(\%)\end{array}$ & S. aureus & $\begin{array}{l}\text { MRSA } \\
(\%)\end{array}$ & $\begin{array}{l}S . \\
\text { aureus }\end{array}$ & $\begin{array}{c}M R S A \\
(\%)\end{array}$ \\
\hline 1 & Pus & 60 & $\begin{array}{l}32 \\
53.33\end{array}$ & 80 & $\begin{array}{l}53 \\
66.25\end{array}$ & 140 & $\begin{array}{l}85 \\
60.71\end{array}$ \\
\hline 2 & Urine & 20 & $\begin{array}{l}04 \\
20.00\end{array}$ & 30 & $\begin{array}{l}08 \\
26.66\end{array}$ & 50 & $\begin{array}{l}12 \\
24.00\end{array}$ \\
\hline 3 & Wound swab & 09 & $\begin{array}{l}04 \\
44.44\end{array}$ & 10 & $\begin{array}{l}06 \\
60.00\end{array}$ & 19 & $\begin{array}{l}10 \\
52.63\end{array}$ \\
\hline 4 & Sputum & 08 & $\begin{array}{l}03 \\
37.50\end{array}$ & 15 & $\begin{array}{l}06 \\
20.00\end{array}$ & 23 & $\begin{array}{l}09 \\
39.13\end{array}$ \\
\hline 5 & Aural swab & 09 & $\begin{array}{l}03 \\
33.33\end{array}$ & 20 & $\begin{array}{l}06 \\
30.00\end{array}$ & 29 & $\begin{array}{l}09 \\
31.03\end{array}$ \\
\hline 6 & Blood & 18 & $\begin{array}{l}02 \\
11.11\end{array}$ & 34 & $\begin{array}{l}03 \\
08.82\end{array}$ & 52 & $\begin{array}{l}05 \\
09.61\end{array}$ \\
\hline 7 & Throat swab & 08 & $\begin{array}{l}02 \\
25.00\end{array}$ & 12 & $\begin{array}{l}03 \\
25.00\end{array}$ & 20 & $\begin{array}{l}05 \\
25.00\end{array}$ \\
\hline 8 & CSF & 00 & $\begin{array}{l}00 \\
00\end{array}$ & 01 & $\begin{array}{l}00 \\
00\end{array}$ & 01 & $\begin{array}{l}00 \\
00\end{array}$ \\
\hline 9 & $\begin{array}{l}\text { Urethral } \\
\text { swab }\end{array}$ & 04 & $\begin{array}{l}01 \\
25.00\end{array}$ & 03 & $\begin{array}{l}01 \\
33.33\end{array}$ & 07 & $\begin{array}{l}02 \\
28.57\end{array}$ \\
\hline 10 & $\begin{array}{l}\text { Bone } \\
\text { cartilage }\end{array}$ & 00 & $\begin{array}{l}00 \\
00\end{array}$ & 02 & $\begin{array}{l}00 \\
00\end{array}$ & 02 & $\begin{array}{l}00 \\
00\end{array}$ \\
\hline 11 & Semen & 03 & $\begin{array}{l}01 \\
33.33\end{array}$ & 02 & $\begin{array}{l}00 \\
00\end{array}$ & 05 & $\begin{array}{l}01 \\
20.00\end{array}$ \\
\hline & Total & 139 & $\begin{array}{l}52 \\
37.68 \\
\end{array}$ & 209 & $\begin{array}{l}86 \\
41.14\end{array}$ & 348 & $\begin{array}{l}138 \\
39.65\end{array}$ \\
\hline
\end{tabular}


Journal of College of Medical Sciences-Nepal, 2010, Vol. 6, No. 1

Table- 2: Resistance to individual antimicrobials in MRSA and MSSA isolated in CMS-teaching hospital, Bharatpur,Nepal

\begin{tabular}{|c|c|c|c|c|c|c|c|}
\hline \multirow[t]{2}{*}{ S. No } & \multirow[t]{2}{*}{ Antimicrobials } & \multicolumn{3}{|c|}{ MRSA } & \multicolumn{2}{|l|}{ MSSA } & Total \\
\hline & & Tested & $\begin{array}{l}\text { Resistance } \\
(\%)\end{array}$ & Tested & $\begin{array}{l}\text { Resistance } \\
(\%)\end{array}$ & Tested & $\begin{array}{l}\text { Resistance } \\
(\%)\end{array}$ \\
\hline \multirow[t]{2}{*}{1} & \multirow[t]{2}{*}{ Penicillin G } & \multirow[t]{2}{*}{126} & 126 & \multirow[t]{2}{*}{189} & 78 & \multirow[t]{2}{*}{315} & 204 \\
\hline & & & 100 & & 41.25 & & 64.76 \\
\hline \multirow[t]{2}{*}{2} & \multirow[t]{2}{*}{ Cephalexin } & \multirow[t]{2}{*}{22} & 18 & \multirow[t]{2}{*}{69} & 25 & \multirow[t]{2}{*}{91} & 43 \\
\hline & & & 81.81 & & 36.23 & & 47.25 \\
\hline \multirow[t]{2}{*}{3} & \multirow[t]{2}{*}{ Ciprofloxacin } & \multirow[t]{2}{*}{83} & 59 & \multirow[t]{2}{*}{138} & 35 & \multirow[t]{2}{*}{221} & 94 \\
\hline & & & 71.08 & & 25.36 & & 42.53 \\
\hline \multirow[t]{2}{*}{4} & \multirow[t]{2}{*}{ Cloxacillin } & \multirow[t]{2}{*}{136} & 96 & \multirow[t]{2}{*}{187} & 80 & \multirow[t]{2}{*}{323} & 127 \\
\hline & & & 70.58 & & 42.78 & & 39.31 \\
\hline \multirow[t]{2}{*}{5} & \multirow[t]{2}{*}{ Erythromycin } & \multirow[t]{2}{*}{62} & 36 & \multirow[t]{2}{*}{124} & 18 & \multirow[t]{2}{*}{186} & 54 \\
\hline & & & 58.06 & & 14.51 & & 29.03 \\
\hline 6 & Gentamicin & 21 & 08 & 65 & 21 & 86 & 29 \\
\hline & & & 38.09 & & 32.30 & & 33.72 \\
\hline 7 & Cefotaxim & 57 & 18 & 118 & 11 & 175 & 29 \\
\hline & & & 31.57 & & 09.32 & & 16.57 \\
\hline 8 & Co-trimoxazole & 44 & 09 & 132 & 13 & 176 & 22 \\
\hline & & & 20.45 & & 09.84 & & 12.50 \\
\hline 9 & Ofloxacin & 68 & 12 & 154 & 18 & 222 & 30 \\
\hline & & & 17.64 & & 11.68 & & 13.51 \\
\hline 10 & Amoxyclav & 28 & 04 & 84 & 07 & 112 & 11 \\
\hline & & & 14.28 & & 08.33 & & 09.82 \\
\hline 11 & Azithromycin & 52 & 05 & 158 & 00 & 210 & 08 \\
\hline & & & 09.61 & & 00 & & 03.80 \\
\hline 12 & Amikacin & 65 & 06 & 112 & 07 & 177 & 13 \\
\hline & & & 09.23 & & 06.25 & & 07.34 \\
\hline 13 & Tetrcyclin & 50 & 04 & 59 & 06 & 109 & 10 \\
\hline & & & 08.00 & & 10.16 & & 09.17 \\
\hline 14 & Vancomycin & 128 & 00 & 186 & 00 & 324 & 00 \\
\hline & & & 00 & & 00 & & 00 \\
\hline
\end{tabular}

\section{Discussion}

MRSA is a global phenomenon with a prevalence rate ranging from $2 \%$ in Netherland and Switzerland, to $70 \%$ in Japan and Hong Kong. ${ }^{11,12}$ In this study, the prevalence of MRSA was found to be $39.6 \%$. Prevalence of MRSA was higher among inpatients $(41.1 \%)$ than outpatients $(37.4 \%)$. This difference could be due to prolonged hospital stay, instrumentation and other invasive procedures. A comparable prevalence rate of $34.7 \%, 31.0 \%$ and $38.5 \%$ were also reported from Assam, Tamil Nadu and Delhi ${ }^{13,14,}$ ${ }^{15}$ whereas, in some studies the rate is comparatively low. In a study in Eastern part of Nepal in Dharan, the rate of MRSA was $(26.4 \%),{ }^{16}$ which was low as compared to this study. In another study in Nagpur the rate of MRSA $(19.5 \%){ }^{17}$ was also low compared to our study. However, in another study it was very high $(80.8 \%) .{ }^{18}$ Analysis from previous studies revealed a relationship between methicillin resistance and 
resistance to other antibiotics. ${ }^{19,20}$ This study showed that all MRSA isolates were significantly less sensitive to antibiotics as compared with MSSA isolates. Many of the isolates were resistant to commonly used antistaphylococcal agents except vancomycin. Anupurba et al. also observed that $32 \%$ of MRSA isolates are resistant to all commonly used antibiotics for $S$. aureus except vancomycin. ${ }^{21}$ Because of the resistance of MRSA to all commonly used antibiotics, it is necessary to test newer group of antibiotics such as vancomycin and teicoplanin routinely. Resistance to (cephalexin) was much higher $(81.8 \%)$ in this study. This is comparable to the study done by Namrata et al. in the eastern part of Nepal who reported the resistant rate to be above (65\%). ${ }^{16}$ Resistance to quinolones (ciprofloxacin) was also high (71\%) in this study . In the study reported by Lahari Sakia et al., the resistant rate was also high $(87.5 \%)$ in Assam. ${ }^{13}$ However, in the same institute, a previous study, in 2001, reported the resistant rate of ciprofloxacin to be only $(22.8 \%) .{ }^{16}$ The rapid emergence of ciprofloxacin is probably due to the indiscriminate and empirical use of these drugs. MSSA isolates shows higher susceptibility to penicillin and cloxacillin $(100 \%$ vs. $41.3 \%)$ and (70.6\% vs. $43.0 \%$ ) respectively than MRSA strains. The epidemiology of MRSA is gradually changing since its emergence was reported. Initially there were occasional reports but now it has become one of the established hospital acquired pathogen. Moreover, the association of multidrug resistance with MRSA had added to the problem. B - lactam antibiotics like penicillin and cephalexin resistance were $100 \%$ and $81 \%$ respectively. Resistance to amino glycosides was more in gentamicin (38\%) than amikacin $(9.2 \%)$ in this study, however, it cannot be recommended for empirical treatment of MRSA associated infections.

Vancomycin seems to be the only antimicrobial agent which showed $100 \%$ sensitivity and may be used as the drug of choice for treating multidrug resistant MRSA infections. However, regular monitoring of vancomycin sensitivity and routine testing of other newer glycopeptides like teicoplanin should be carried out. Further, the regular surveillance of hospital associated infections including monitoring antibiotic sensitivity pattern of MRSA and formulation of definite antibiotic policy may be helpful for reducing the incidence of MRSA infection.

\section{Conclusion}

This preliminary report showed a high prevalence of MRSA in our hospital. There is a need for surveillance of MRSA and its antimicrobial profile. The hospital infection control policy and guidelines that already exists should be strictly implemented and followed so as to enable the clinicians to deliver better and proper health care to the patients.

\section{References}

1. Duckworth G.J. Diagnosis and management of methicillin resistant Staphylococcus aureus infection. BMJ1993; 307: 1049-52.

2. Bradley JM, Noone P, Townstend DE et al, Methicillin resistant Staphylococcus aureus in a London Hospital. Lancet 1985; 1: 1493-5

3. Gordon J. Clinical significance of methicillin sensitive and methicilin resistant Staphlococcus in UK Hospitals and the relevance of povidone iodine in their control.Postgrad Med J 1993; 69 (Suppl 3); 106-16. 
4. Manual on antimicrobial resistance and susceptibility testing. WHO Antimicrobial resistance monitoring programme. WHO Geneva. 1997.

5. Mathur SK, Singal S, Prasad KN, et al. Prevalence of Methicillin resistant Staphylococcus aureus (MRSA) in tertiary care hospital. Indian J Med Microbiology 1994; 12(2): 96-101.

6. Udaya Shankar C, Harish BN, Umesh Kumar PM, et al. Prevalence of Methicillin resistant Staphylococcus aureus in JIPMER Hospital - A preliminary report. Indian J Med Microbiol 1997;15(3):137-8

7. Burgner D, Dalton D, Hanlon M, Wong M, et al. Repeated prevalence surveys of Paediatric hospitalacquired infection. J Hosp Infect 1996; 34(3):163-70.

8. Leroyer A, Bedu A, Lombrail P, et al. Prolongation of hospital stay and extra costs due to hospital acquired infection in a neonatal unit.J Hosp Infect 1997; $35(1): 37-45$.

9. Baird D. Staphylococcus. Cluster forming gram negative cocci. Mackie and McCartney Practical Medical Microbiology. $4^{\text {th }}$ ed, 2;1996;245-58.

10. Clinical and Laboratory Standards Institute. Performance standards for antimicrobial susceptibility testing; $16^{\text {th }}$ information supplement (M100-S16). Clinical and Laboratory Standards Institute, Wayne, Pa: 2006.

11. Fluit AC, Wielders CL, Verhoef JF, et al. Epidemiology and Susceptibility of 3,051 Staphylococcus aureus isolates from 25 University Hospitals participating in the European SENTRY Study. J Clin Microbiol 2001; 39:3727-32.

12. Diekema DJ, Pfaller MA, Schmitz FJ, et al. Survey of Infections Due to Staphylococcus Species: Frequency of Occurrence and Antimicrobial Susceptibility of Isolates Collected in the United States, Canada, Latin
America, Europe and the Western Pacific Region for the SENTRY Antimicrobial Surveillance Program, 1997-1999. Clin Infect Dis 2001; 32:S114-32.

13. Saikia L, Nath R Choudhary B, et al. Prevalence and antimicrobial susceptibility pattern of methicillinresistant Staphylococcus aureus in Assam. Indian J Crit Care Med 2009; 13:156-8.

14. Rajaduraipandi K, Mani KR,Panneerselvam K, et al. Prevalence and antimicrobial susceptibility pattern of methicillin-resistant Staphylococcus aureus. A multicentric study. Ind J Med Microbiol 2006; 24:348 .

15. Mohanty S, Kapil A, Dhawan B, et al. Bacteriological and antimicrobial susceptibility profile of soft tissue infections from Northern India. Ind J Med Sci 2004; 58:10-5.

16. Kumari N, Mohapatra TM, Singh YI. Prevalence of Methicillin resistant Staphylococcus aureus in a Tertiary-Care Hospital in Eastern Nepal. J Nepal Med Assoc.2008 Apr-Jun; 47(170):53-6.

17. Tahnkiwale SS, Roy S, Jalgaonkar SV. Methicillin resistance among isolates of staphylococcus aureus: Antibiotic sensitivity pattern and phage typing. Ind $J$ Med Sci 2002; 56:330-4.

18. Verma S, Joshi S, Chitnis V, et al. Growing problem of methicillin resistant staphylocci: Indian Scenario. Ind J Med Sci 2000; 54:535-40.

19. Majumder D, Bordoloi JN, Phukan AC, et al. Antimicrobiol susceptibility pattern among methicillin resistant staphylococci isolates in Assam. Indian J Med Microbiol 2001; 19:138-40.

20. Vidhani S, Mehndiratta PL, Mathur MD.Study of MRSA isolates from high risk patients. Indian J Med Microbiol 2001; 19:87-90.

21. Anupurba S, Sen MR, Nath G, et al. Prevalence of methicillin resistant staphylococcus aureus in a Tertitiary Care Referral Hospital in Eastern Uttar Pradesh. Indian J Med Microbiol 2003; 21:49-51 